\title{
FACTUALIDADE X REALIDADE: UM ESTUDO SOBRE OS RELATOS QUE CONTRIBUÍRAM PARA A ORIGEM DOS CRIADORES DE LOBISOMENS
}

\author{
Ana Luísa Gusmão da Rocha Dalben \\ Universidade do Oeste Paulista - UNOESTE, Especialização Lato Sensu em Jornalismo e Literatura, \\ Presidente Prudente, SP. E-mail: analuisa.dalben@gmail.com
}

\begin{abstract}
RESUMO
A presente pesquisa tem como objetivo analisar os relatos de aparições do Lobisomem em Joanópolis, cidade no interior do estado de São Paulo, conhecida como capital nacional do Lobisomem. Sua proposta contributiva consiste na interpretação dos depoimentos que trarão em paralelo um panorama do contexto religioso local em que o mito do Lobisomem se desenvolveu. Para tanto, a abordagem metodológica adotada é a pesquisa qualitativa e as técnicas utilizadas são a pesquisa bibliográfica e documental, em especial as narrativas folclóricas que foram previamente coletadas e condensadas no livro Lobisomem: assombração e realidade. Este foi o livro que contribuiu para a criação da Associação dos Criadores de Lobisomens, organização que reaproveita e projeta os mitos folclóricos para promover o turismo do imaginário na cidade.

Palavras-chave: Lobisomem, Joanópolis, Folclore, Mito, Associação dos Criadores de Lobisomem.

\section{FACTUALITY X REALITY: A STUDY OF THE STORIES THAT CONTRIBUTED TO THE ORIGIN OF THE CREATORS OF WEREWOLVES}

\begin{abstract}
This research aims to analyze the Werewolf sightings' reports at Joanópolis, city in the state of São Paulo, known as national Werewolf capital. Its contribution proposal is the interpretation of those statements that will bring in parallel an overview of the local religious context in which the myth of werewolf was developed. Therefore, methodological approach adopted is the qualitative research. The technique chosen was the bibliographic and documentation research, in particular the folk narratives that were previously collected and condensed in the book Werewolf: haunting and reality. This is the book that contributed to the creation of the Association of the Creators of Werewolves, an organization that reuses and projects the folk myths to promote the tourism of imagination in the city.
\end{abstract}

Keywords: Werewolf, Joanópolis, Folk, Myth, Association of the Creators of Werewolf; 


\section{INTRODUÇÃO}

O jornalismo diferencia-se da literatura pelo processo de apuração rigorosa dos fatos e das versões ao contar uma história. O professor doutor em Literatura Brasileira Marcelo Bulhões (2007, p.21) em aquiescência com a afirmação anterior, diz que o jornalismo travestiu-se através do percurso de sua história por algumas crenças, como:

a de que é possível ter acesso aos contornos exatos do real efêmero da vida e transmiti-lo com autenticidade; a de que se pode captar esse real fugidio do cotidiano, preservando-o de modo inequívoco; a de que o jornalista é transmissor legitimo da realidade dos acontecimentos. E mais: a crença em ferramentas ou procedimentos capazes de registrar esse real e remetê-lo sem engano.

Ora, o jornalismo é uma narrativa baseada em fatos. E o jornalismo literário, é a aliança das ferramentas de apuração do jornalismo com o estilo da narrativa da literatura. Pena (2006, p.105) traz a luz algumas das técnicas inspiradas pela literatura: "imersão do repórter na realidade, voz autoral, estilo, precisão de dados e informações, uso de símbolos (inclusive metáforas), digressão e humanização.".

As técnicas da literatura na narrativa de não-ficção, como também é chamado o jornalismo literário, está nas grandes reportagens, na construção dos perfis nas biografias, nas crônicas, assim como nos relatos de viagem. Esses gêneros estão no limiar entre literatura e jornalismo.

Tendo em vista o interesse em pesquisar especialmente sobre as narrativas folclóricas como forma de jornalismo literário, a proposta desta pesquisa é reunir informações sobre os relatos do mito do lobisomem em Joanópolis, cidade que foca parte de seu turismo ao chamado "turismo do imaginário", por meio da pesquisa exploratória, e separar a lenda dos fatos.

Diante do interesse da pesquisadora com a região e em aprofundar os conhecimentos sobre jornalismo literário, o presente artigo visa utilizar a prática jornalística da apuração, aqui no caso por meio de documentos, para desnudar o mito do lobisomem e traçar a fronteira entre a realidade e a imaginação. O que se busca é tentar visualizar o fato que deu origem a lenda, relevante para o jornalismo que se propõe a relatar a verdade e separar fatos históricos de lendas.

\section{METODOLOGIA}

Pedro Demo $(p .19,1985)$ define bem o que é metodologia e a sua importância para a pesquisa científica: "Metodologia é uma preocupação instrumental. Trata das formas de se fazer ciência. Cuida dos procedimentos, das ferramentas, dos caminhos. A finalidade da ciência é tratar a realidade teórica e praticamente. Para atingirmos tal finalidade, colocam-se vários caminhos. Disto trata a metodologia.".

Escolher a metodologia a ser adotada é definir aonde se quer chegar. Pois bem, o procedimento escolhido para tornar possível a realização deste trabalho é a pesquisa qualitativa. Segundo Goldenberg (1997) na pesquisa qualitativa a preocupação não se dá em relação à representatividade numérica, mas ao aprofundamento da compreensão de um grupo social, no caso, os relatos do mito do lobisomem em Joanópolis, situada ao norte do Estado de São Paulo. Tal caminho é adequado quando a realidade do que se visa descobrir, mediante a coleta de dados, não pode ser traduzida em números. Não importa aqui quantos relatos são, mas aclarar o fato por trás da lenda.

Quanto ao método, "[...] é o conjunto das atividades sistemáticas e racionais que com maior segurança e economia, permite alcançar o objetivo - conhecimentos válidos e verdadeiros , traçando o caminho a ser seguido detectando erros e auxiliando as decisões do cientista". (LAKATOS \& MARCONI, 1990b, p.82) Trata-se da ferramenta escolhida para trazer luz ao objeto do estudo. 
A pesquisa qualitativa pode, no entanto, valer-se de diversos instrumentos de estudo. A pesquisa bibliográfica é um destes instrumentos, cuja técnica será empregada no presente projeto, pois a pesquisadora precisa conhecer o que já foi publicado sobre o assunto para estabelecer as bases em que avançarão. A pesquisa documental é outro instrumento, haja vista que documentos como jornais, revistas e dossiês, por exemplo, são importantes fontes de dados.

A diferença entre a pesquisa bibliográfica e a documental pode ser compreendida pela explanação de Godoy, "[...] os documentos constituem uma rica fonte de dados. O exame de materiais de natureza diversa, que ainda não receberam um tratamento analítico, ou que podem ser reexaminados, buscando-se novas e/ ou interpretações complementares, constitui o que estamos denominando pesquisa documental.".

Para Cellard (2008, p.295) o uso dos documentos justifica-se quando a compreensão do objeto pesquisado necessita, para o seu melhor entendimento, de contextualização história e sociocultural. Como no caso em tela, colher a história que primeiramente foi vivida e depois narrada por gerações:

[...] o documento escrito constitui uma fonte extremamente preciosa para todo pesquisador nas ciências sociais. Ele é, evidentemente, insubstituível em qualquer reconstituição referente a um passado relativamente distante, pois não é raro que ele represente a quase totalidade dos vestígios da atividade humana em determinadas épocas. Além disso, muito frequentemente, ele permanece como o único testemunho de atividades particulares ocorridas num passado recente.

\section{RESULTADOS}

Como trabalho de conclusão na Escola de Folclore, Maria do Rosario de Souza Tavares de Lima dedicou-se a coletar informações sobre os mitos, passados por tradição oral e narrados especialmente em Joanópolis, cidade em proximidade com a divisa do estado de Minas Gerais. Os resultados de suas pesquisas de campo estão condensados em um livro que foi a base de partida documental deste artigo.

Os informantes do trabalho da folclorista Lima (1983, p.15):

"viajam para a Capital, para cidades vizinhas, para Aparecida do Norte no Vale do Paraíba (SP). Alguns conhecem a cidade do Rio de Janeiro (RJ) e outras localidades fora do Estado de São Paulo. A informante mais idosa reside agora na periferia da Capital. [...] São todos naturais da região; a maioria, do local da pesquisa; dois, do vizinho município de Piracaia. Alguns descendem de mineiros, outros de italianos.".

De acordo com a pesquisa de campo de Lima (1983), tanto o homem do campo quanto o residente nos aglomerados urbanos, por meio da tradição oral contribuíram para a perpetuação dos mitos, como o da bruxa, da mula-sem-cabeça, do curupira, e em especial, o objeto desta pesquisa, o Lobisomem.

De acordo com a pesquisa bibliográfica estrangeira levantada por Lima (1983, p.51), "o Lobisomem chegou até o Brasil trazido da Europa, através de Portugal.". E também surgiu em Joanópolis por meio do europeu. Segundo a historiadora joanopolense, Terry Harris apud Neri (2010, p.4), "a cidade foi fundada no final do século XIX, por imigrantes europeus, principalmente portugueses, e posteriormente abrigou muitos italianos que vieram ao país para trabalhar nas lavouras de café.".

Uma característica de grande expressividade em Portugal e na Itália é a religiosidade, e assim, Joanópolis herdou fortemente essa particularidade dos seus fundadores, países de maioria predominantemente católica. Lima (1983, p.14) aponta que "Observam-se facilmente 
manifestações de catolicismo folclórico." nesta cidade do interior paulista onde a religião fundiuse ao imaginário popular da sociedade caipira para dar espaço aos mitos.

\section{DISCUSSÃO}

Lima (1983, p.17) conceitua mito como relato, narrativa sobre seres sobrenaturais, "com menção às suas características e ações ou atividades. [...] Sua veracidade estava sempre na dependência da sua antiguidade: quanto mais antigo, mais verdadeiro".

Eliade explica que há outra perspectiva para o significado de mito "onde o mito designa, ao contrário, uma 'história verdadeira' e, ademais, extremamente preciosa por seu caráter sagrado, exemplar e significativo." (2011, p.7). É verdade que usualmente emprega-se a palavra mito como ficção, para tudo o que não poderia existir no âmbito da realidade.

É nesta fronteira que está o lobisomem, objeto desta pesquisa. Ficção e realidade. Observando os relatos dos informantes no grupo social onde Lima (1983) coletou os depoimentos, o lobisomem, é - ou foi, ao menos na época da pesquisa da folclorista - real. Para Eliade, o mito é "'vivo', no sentido de que fornece os modelos para a conduta humana, conferindo, por isso mesmo, significação e valor à existência." (2011, p.8).

Os seres humanos foram descritos por Sunwolf como "criaturas que contam histórias" (2005, p.305). E segundo Fisher apud Sunwolf (2005, p. 305/306) o ser humano pode ser melhor entendido como "homo narrans, pois organizamos nossas experiências em histórias que têm tramas, personagens centrais e sequências de ação que trazem lições implícitas e explícitas. (grifo do autor)".

O cenário de uma cidade pequena com clima temperado para frio, onde "aproximadamente metade da população ainda vive nos bairros rurais e sítios nos arredores do centro urbano (Neri, 2010, p.4) cercada pela mata da Serra da Mantiqueira e conforme Lima $(1983$, p.12) cuja boa parte da população é procedente da "colônia italiana [...] ali significativa e operosa. A ela pertencia o médico, assim como o marceneiro [...] Deixaram descendentes que ainda residem no local" foi um fator que influenciou o homo narrans para contar histórias de lobisomem.

Embora, Lima (1983, p.21) afirme que o mito folclórico nunca se situa no contexto religioso e não é objeto de veneração, após a leitura e interpretação dos muitos relatos, por ela levantados, não se pode descartar a hipótese que tais mitos tenham uma função religiosa, como trazer lições implícitas para que os homens católicos saibam como se comportar. Não há relatos de lobisomens mulheres no Brasil, contudo, estas também não escapam da arma que pode ter sido utilizada pela Igreja para os cristãos, como crítica ao paganismo, por exemplo.

Observe-se como o mito folclórico do lobisomem se manifesta em Joanópolis:

"No lugar da pesquisa, é o filho mais moço de uma série de sete homens. Para livrar-se do fadário (maldição) deve, segundo alguns informantes, ser batizado pelo irmão mais velho e, [...] mais tarde deverá ser padrinho de crisma do irmão que o batizou, para confirmar. [...] Se assim acontecer, não se transformará em Lobisomem. [...] Uns dizem que é castigo ou penitência que Deus dá. Outros acham que isso acontece por artes do Diabo [...] Homem que fica 10 anos sem se confessar e comungar ou sem pôr a mão na água-benta, não se livra do fadário. Quem falta ao respeito com os pais ou padrinhos pode também virar Lobisomem; se for mulher, vira Bruxa." (Lima, 1983, p.27, grifo do autor)

E embora, não exista uma nova coleta de relatos de uma amostra da população domiciliada no cenário atual de Joanópolis, sabe-se conforme dossiê enviado pelo professor e historiador, especializado em folclore, Valter Cassalho a esta pesquisadora que: 
“Em 1998 o Lobisomem voltou à tona, através do comercial [...] do [...] MacDonald's, no qual figuraram pessoas de nossa cidade. Surgiu então a LOBOMANIA, confeccionando camisetas, adesivos e eventos, nascendo aí a [...] Associação dos Criadores de Lobisomens, com o intuito de difundir este precioso mito."

Desde então, os Criadores de Lobisomens aproveitam o folclore e relembram o grande número de histórias de assombração, canções e costumes para divulgar este município do interior paulista e atrair o turismo. O sentido essencial de difundir o mito desta vez, não é mais religioso e sim econômico.

\section{REFERÊNCIAS}

BAHIA, Juarez. Jornal, história e técnica. São Paulo: Ática, 1998.

BULHÕES, Marcelo. Jornalismo e literatura em convergência. São Paulo: Ática, 2007.

CELLARD, A. A análise documental. In: POUPART, J. et al. A pesquisa qualitativa: enfoques epistemológicos e metodológicos. Petrópolis, Vozes, 2008.

DUARTE, Jorde; BARROS, Antonio. Métodos e técnicas de pesquisa em comunicação. 2. ed. São Paulo: Editora Atlas, 2009.

DUNDES, Alan. Morfologia e estrutura no conto folclórico. São Paulo: Perspectiva, 1996.

ELIADE, Mircea. Mito e realidade. 6.ed. São Paulo: Perspectiva, 2011.

FEBVRE, Lucien. Combates pela história. Lisboa: Editorial Presença, 1989.

GODOY,Arilda Schmidt. Introdução à pesquisa qualitativa e suas possibilidades. RAE - Revista

de Administração de Empresas, São Paulo, v. 35, n. 2, p. 57-63, 1995.

GOLDENBERG, Mirian. A arte de pesquisar: como fazer pesquisa qualitativa em ciências sociais. Rio de Janeiro: Record, 1997.

LAKATOS, Eva Maria; MARCONI, Maria de Andrade. Fundamentos de Metodologia Científica. 2.ed. São Paulo: Editora Atlas,1990a.

LAKATOS, Eva Maria; MARCONI, Maria de Andrade. Técnicas de pesquisa. 2.ed. São Paulo: Editora Atlas, 1990b.

LIMA, Edvaldo Pereira. O que é livro-reportagem. São Paulo: Brasiliense 1993.

LIMA, Maria do Rosario de Souza Tavares de. Lobisomem: assombração e realidade. São Paulo: Escola de Folclore, 1983.

NERI, Renato Aquino. "Ser caipira é ser feliz": Um passeio pelas terras baixas da Serra da Mantiqueira em Joanópolis - SP. 2010. 37 f. Monografia (Especialização) - Faculdade de Filosofia, Letras e Ciências Humanas, Universidade de São Paulo. 
PENA, Felipe. Jornalismo Literário. São Paulo: Contexto, 2006.

ROSSI, Clóvis. O que é jornalismo. 10.ed. São Paulo: Brasiliense, 2005.

SUNWOLF, J. D.. Era uma vez, para a alma: uma revisão dos efeitos do storytelling nas tradições religiosas. Comunicação \& Educação, São Paulo, v. 10, n. 3, p. 305-325, dec. 2005. ISSN 2316-9125. Disponível em: <http://www.revistas.usp.br/comueduc/article/view/37544/40258>. Acesso em: 9 aug. 2016. doi:http://dx.doi.org/10.11606/issn.2316-9125.v10i3p305-325.

https://doi.org/10.11606/issn.2316-9125.v10i3p305-325

THOMPSON, Paul. A voz do passado: história oral. São Paulo: Paz e Terra, 1992. 